\title{
Rock support testing in Luossavaara-Kiirunavaara AB's underground mines, Sweden
}

\author{
E Swedberg Luossavaara-Kiirunavaara $A B$, Sweden \\ F Thyni Luossavaara-Kiirunavaara $A B$, Sweden \\ J Töyrä Luossavaara-Kiirunavaara $A B$, Sweden
}

A Eitzenberger Luleå University of Technology, Sweden

\begin{abstract}
The mining company Luossavaara-Kiirunavaara $A B$ (LKAB) operates two underground iron ore mines in Sweden. Both mines use large scale sublevel caving to extract the ore at a depth of nearly one kilometre and are, since 2008, regarded as seismically active. Rock support is therefore essential in order to maintain safe and accessible production areas. The support system used by LKAB primarily consists of steel fibre reinforced shotcrete together with external steel mesh and rockbolts. Accurate methods for design and testing of the support elements are important parts of ensuring the stability of the system.
\end{abstract}

This paper explores three aspects of the design and testing of rock support, namely:

1. The early strength development for grouted rockbolts and shotcrete.

2. The impact of shotcrete thickness.

3. The placement of the steel mesh (i.e. embedded or external) on the load bearing capacity of a rock support system.

Pull-out tests on rockbolts and stud penetration tests in a shotcrete liner were conducted in the field, while round determinate panel (RDP) tests were performed in a laboratory environment. RDP tests were performed on fibre reinforced shotcrete panels with and without external steel mesh, as well as shotcrete panels with and without steel fibres reinforced with embedded steel mesh.

The pull-out tests show that it takes about $19 \mathrm{~h}$ for a grouted rebar bolt to achieve its failure load capacity, while it takes $15 \mathrm{~h}$ from application for the shotcrete liner to obtain about $70 \%$ of the required energy absorption. Results from the RDP tests indicate that the bearing capacity of a rock support system is highly influenced by the shotcrete thickness. Doubling the shotcrete thickness results in a threefold increase of the residual load capacity, suggesting that the residual strength increases with shotcrete thickness by a polynomial function. Shotcrete panels with embedded steel mesh are shown to be able to sustain higher peak loads compared to panels with external steel mesh in these tests. However, at large deflections the reverse occurs, i.e., the latter panel type has a higher load bearing capacity.

\section{$1 \quad$ Introduction}

LKAB owns and operates the Kiirunavaara and Malmberget underground iron ore mines in northern Sweden. Both mines use large scale sublevel caving to extract the ore and have been in operation for approximately one hundred years. The total crude ore production from both mines amounts to approximately $50 \mathrm{~m}$ t per year.

Production is currently performed at depths approaching one kilometre. The large scale mining method used causes significant changes to the in situ stress state, as illustrated in Figure 1 (Sjöberg et al. 2003). At current production levels, the mining-induced major principal stress is approximately twice the magnitude of the in situ (non-disturbed) stress state. 
Over time, the requirements of ground support in the mines have changed. Since 2008, the rock support standards include support designed for seismically-induced dynamic loads. The dynamic support consists of $100 \mathrm{~mm}$ thick steel fibre reinforced shotcrete, externally mounted welded steel mesh and grouted yieldable rockbolts. For more details about the implementation of the support system, the reader is referred to Jacobsson et al. (2013).

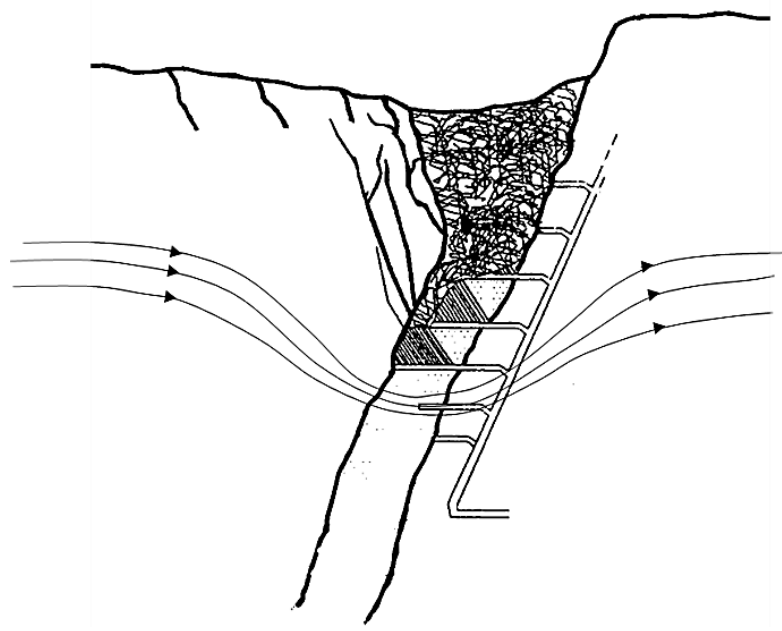

Figure 1 Illustration of the mining induced rock stress state in LKABs underground mines, after Sjöberg et al. (2003)

The function of the support system as a whole is highly dependent on the capacity of the individual support elements. Therefore, accurate and relevant methods of testing support elements are important in order to design a stable and efficient support system.

This paper describes three aspects related to the design and testing of rock support. The first concerns the development of early strength for cement-grouted rockbolts and fibre reinforced shotcrete. Also, the impact of shotcrete thickness and mesh placement (external or embedded) on the overall strength of a shotcrete-steel mesh lining is considered.

\section{$2 \quad$ Methods for testing of rock support}

Tests using three different methods are described in this paper. RDP tests are used to quantify the flexural toughness of shotcrete. Stud penetration tests are performed to measure uniaxial compressive strength of fresh shotcrete in the field. Pull-out testing of rockbolts provides a value of the bond strength of the bolt-grout interface.

\subsection{Round determinate panel tests}

The tests on the shotcrete panels were performed using the procedure specified in the ASTM C1550-12 standard (ASTM International 2012). This standard describes a test method for measuring the flexural toughness of fibre reinforced shotcrete, defined as the energy absorbed by the shotcrete panel during loading. The absorbed energy is calculated from the area under the load deflection curve between the onset of loading and a certain deflection interval of the panel (ASTM International 2012).

LKAB has a requirement that the shotcrete used for dynamic rock support in the underground mines must have a minimum toughness of $490 \mathrm{~J}$ at $40 \mathrm{~mm}$ deflection when tested according to ASTM C1550 (ASTM International 2012). The value of $490 \mathrm{~J}$ at $40 \mathrm{~mm}$ deflection is valid for test panels where the shotcrete is sprayed in the moulds. For ASTM C1550 test panels where the shotcrete is cast in the moulds, the minimum value of the toughness is set by LKAB to $650 \mathrm{~J}$ instead. The higher value is used in order to correct for differences between sprayed and cast concrete, for example with regard to fibre orientation in the shotcrete. 
The test is performed by applying a point load centrally on a circular panel of sprayed or casted shotcrete (Figure 2) with a thickness of $75 \mathrm{~mm}(-5 /+15 \mathrm{~mm})$ and diameter of 800 ( $\pm 10 \mathrm{~mm})$. The load on the shotcrete panel is applied vertically from above through a hemispherical-ended piston that advances at a constant speed of about $4 \mathrm{~mm} / \mathrm{min}$. During the test, the applied load is recorded together with the deflection at the edge of the piston. The shotcrete panels are supported by three symmetrically positioned supports with pivot joints (Figure 2 ) in the test rig. The supports are positioned along a circle with a radius of $375 \mathrm{~mm}$, with $120^{\circ}$ angle between each support (ASTM International 2012).

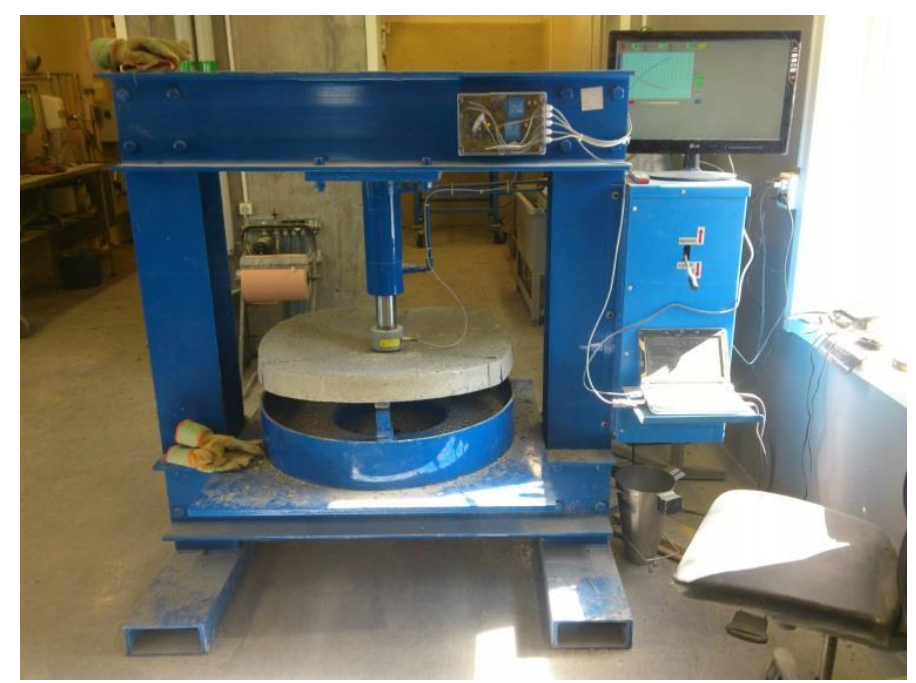

Figure 2 Testing equipment for RDPs according to ASTM C1550 (ASTM International 2012)

\subsection{Stud penetration tests}

The stud penetration method is used to measure the uniaxial compressive strength (UCS) of fresh concrete. It is performed by firing nails into the concrete using a stud driver, with the penetration of the nails being used together with calibration curves to calculate the UCS. There are several variants of the method: some include the measurement of pull-out force, for example as described by the standard SS-EN 14488-2 (Swedish Standards Institute 2006), while others only measure penetration. For the tests described in this article, only penetration is measured and calibration curves have been created for a range of UCS between 2 and $26 \mathrm{MPa}$. Figure 3 shows an RDP where the stud penetration method has been used to measure the UCS of the panel.

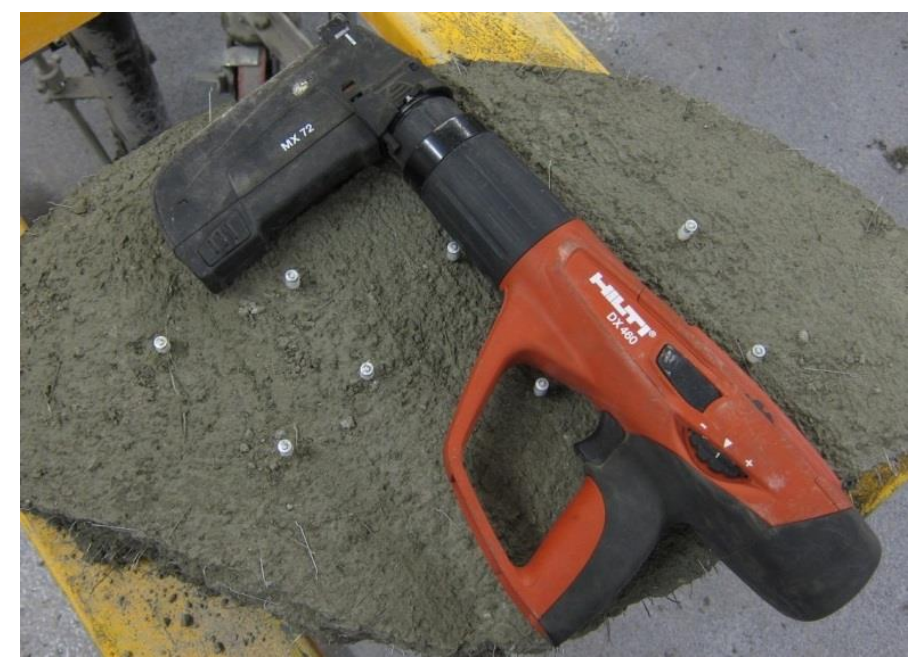

Figure 3 Testing of RDP panels using the stud driving method 


\subsection{Pull-out testing of rockbolts}

Pull-out testing of rockbolts is one of the most commonly used methods to determine bond strength of an installed bolt. For these tests, a tripod was used together with a cylinder and a hand pump. The maximum load capacity of the cylinder was $320 \mathrm{kN}$, which is more than enough to fail a $20 \mathrm{~mm}$ rebar bolt. Figure 4 shows the equipment used to load the rockbolts.

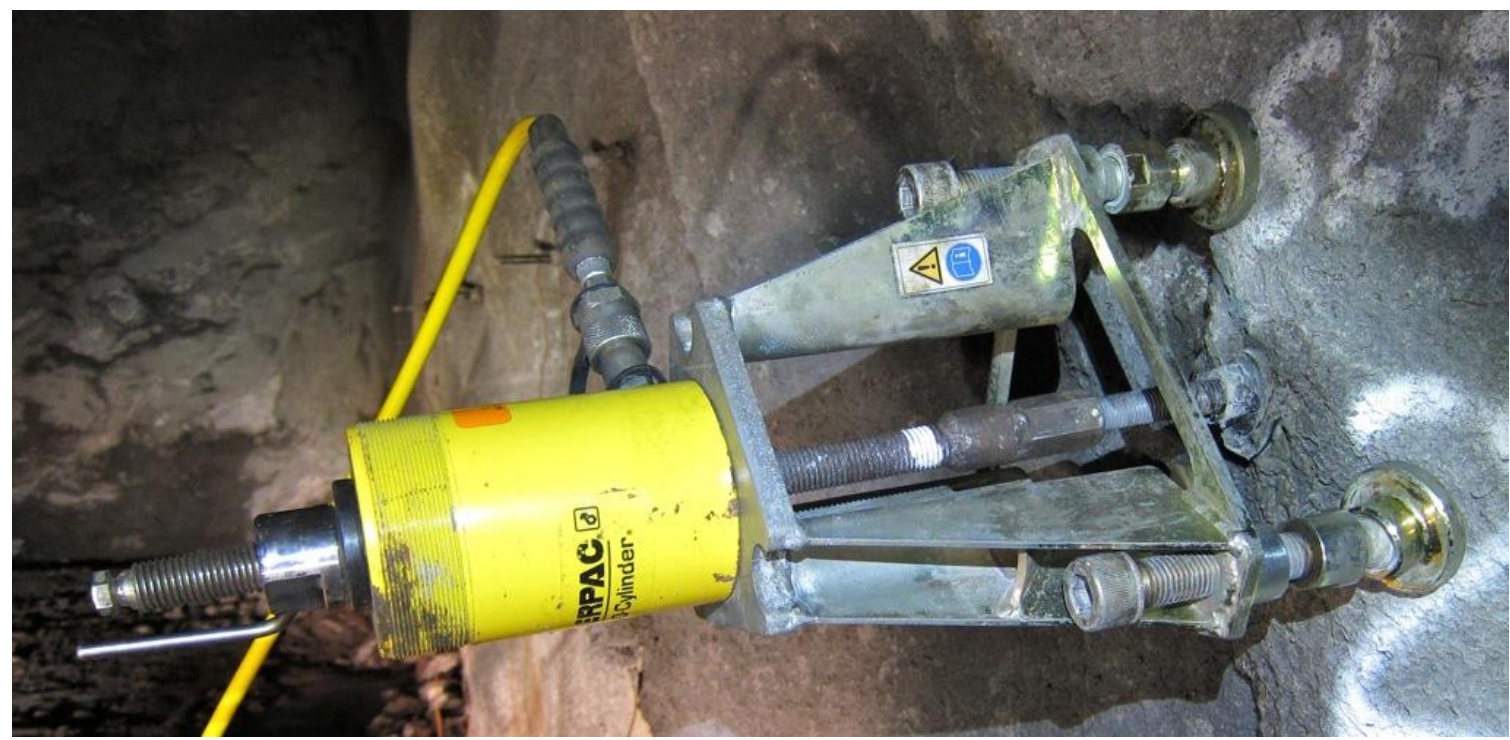

Figure 4 The cylinder and tripod used for pull-out testing of rockbolts

Since the bond strength between a rebar bolt and the grout is, in general, stronger than the failure load of the bolt itself, the pull-out tests were performed with bolts of reduced embedment length. For this reason, a number of rebar bolts (as per Figure 5) were specially designed and manufactured. These were made with a plastic sleeve covering the entire bolt, apart from the anchoring section. The specifications of the test bolts are listed in Table 1 . In situ, the bolts were cement-grouted and installed with bolting jumbos as normally practiced in LKAB's mines.

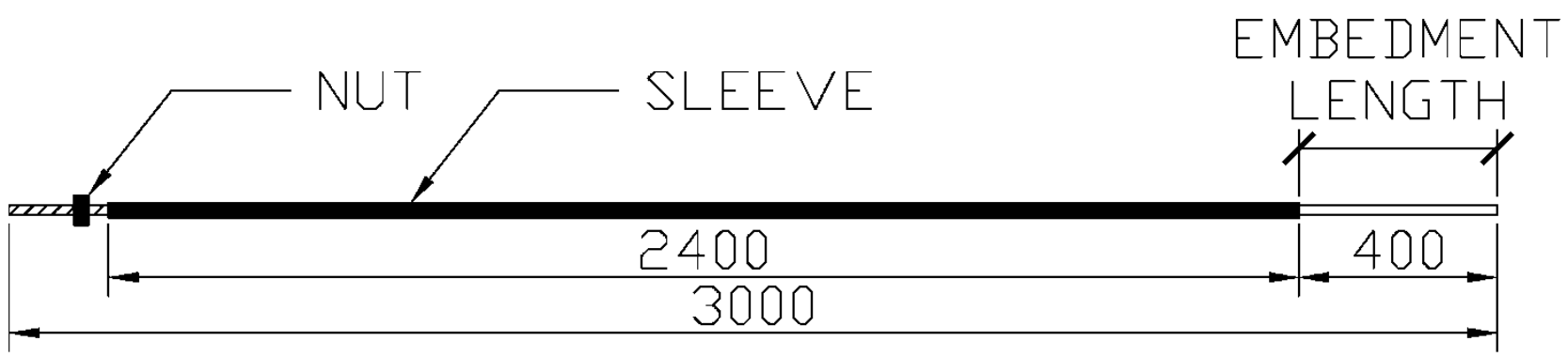

Figure 5 The specially prepared testing bolts with reduced embedment length

Table 1 Specifications for the bolts used in the pull-out tests (Swedberg 2013)

\begin{tabular}{cc}
\hline Material & B500BT rebar \\
\hline Diameter & $20 \mathrm{~mm}$ \\
Length & $3,000 \mathrm{~mm}$ \\
Yield load & $170 \mathrm{kN}$ \\
Failure load & $199 \mathrm{kN}$ \\
\hline
\end{tabular}


The embedment length of rockbolts installed in normal production is $800 \mathrm{~mm}$. In order to compare the results from pull tests made with different embedment lengths, the failure load is divided with the surface area of the embedded section. This gives a value for the required shear resistance $\left(\tau_{b}\right)$ between the bolt and the grout as:

$$
\tau_{b}=\frac{F_{b}}{A_{b}}=\frac{199}{0.8 \cdot \pi \cdot 20}=3.95 \approx 4.0 \mathrm{MPa}
$$

Where:

$F_{b} \quad=$ the failure load of the rockbolt.

$A_{b}=$ the embedded surface area of the rockbolt.

\section{Early strength of shotcrete}

Since fibre reinforced shotcrete is generally applied directly after each tunnel development round, the early strength is of interest primarily for the immediate support effect. In addition, drilling through a shotcrete lining which has not had time to achieve sufficient strength can damage the lining.

Determination of the early strength development has been performed with two methods, RDP tests on panels cast in laboratory and stud penetration tests on a shotcrete lining in the field. The RDP tests were performed according to the procedure described earlier.

\subsection{RDP tests for determination of early strength}

A total of 24 RDP tests, divided into two series, were performed for evaluating the development of flexural toughness for the fibre reinforced shotcrete. All panels were cast under laboratory conditions from the same concrete mix that is used for application of shotcrete. The only difference is the lack of accelerator, since this is added in the spraying rig. Details about the two series are given in Table 2 . In order to be able to compare the results to field conditions, the uniaxial compressive strength was measured using the stud penetration method on the panels in the second series after the RDP tests.

Table 2 Details about the two series of RDP tests performed for evaluation of development of flexural toughness for fibre reinforced shotcrete (Swedberg 2013)

\begin{tabular}{ccc}
\hline & Series 1 & Series 2 \\
\hline Number of panels & 12 & 12 \\
Curing time interval & $12-22 \mathrm{~h}$ & $14-44 \mathrm{~h}$ \\
Reinforcement & $10 \mathrm{~kg} / \mathrm{m}^{3}$ polypropylene fibres & $40 \mathrm{~kg} / \mathrm{m}^{3}$ steel fibres \\
\hline
\end{tabular}

Energy absorption capacities as a function of curing time for the RDP tests are presented in Figure 6. Rapid strength development starts after 12-14 h, and levels out after 20-24 h. The highest observed energy absorption capacities (approximately $630 \mathrm{~J}$ ) are measured after $36 \mathrm{~h}$ for both series.

The stud penetration tests show an exponential relationship between penetration and energy absorption capacity $(E)$ measured with an RDP test on a cast shotcrete panel, as shown in Figure 7 . This relationship has the equation:

$$
E(x)=1530 e^{-0,0538 x}
$$

Where:

$x=$ the penetration in millimetres measured using the stud driving method. 


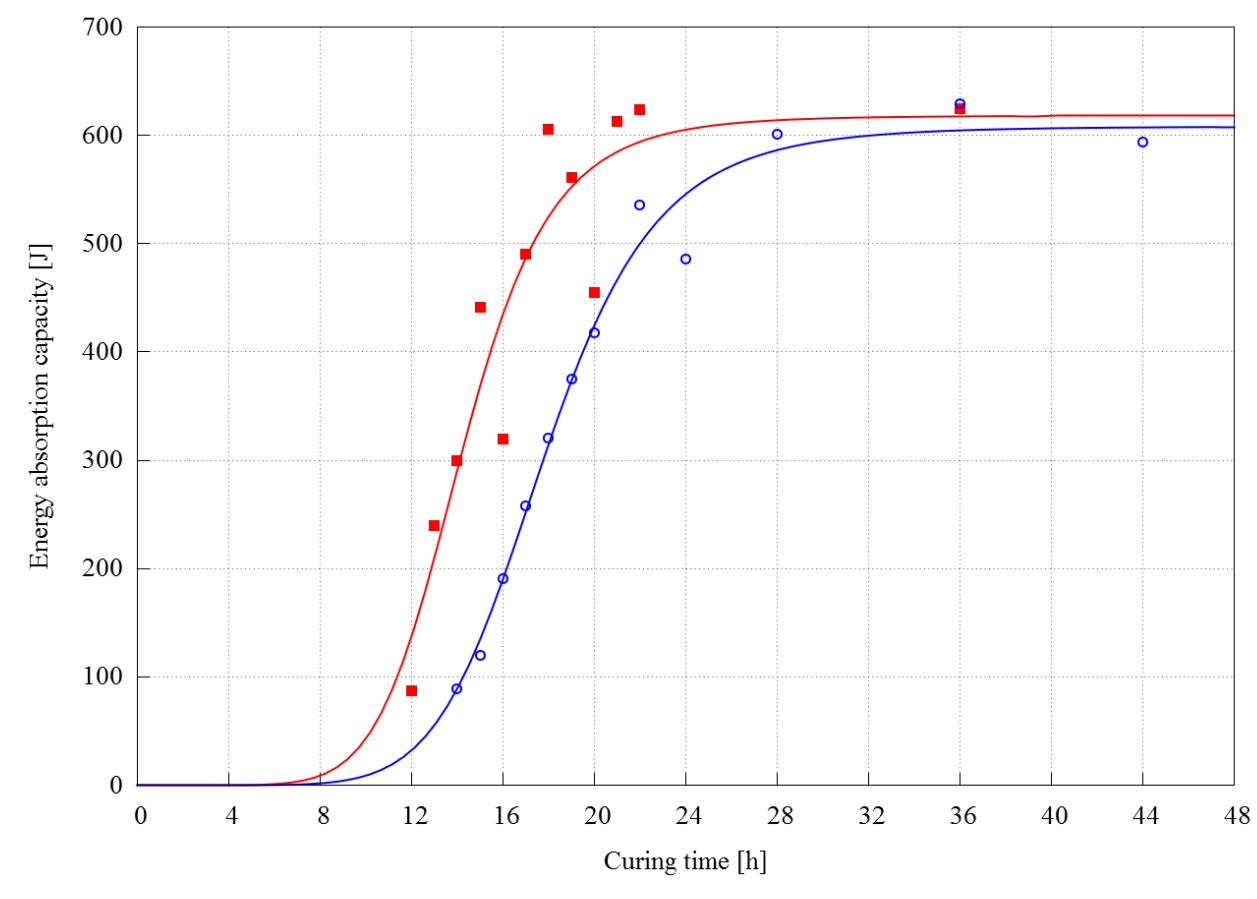

$\mathrm{RDP}$ tests series $1 \quad$ - $\mathrm{RDP}$ tests series 2 。

Figure 6 Energy absorption capacity at $40 \mathrm{~mm}$ deflection as a function of curing time for the RDP panel tests, after Swedberg (2013)

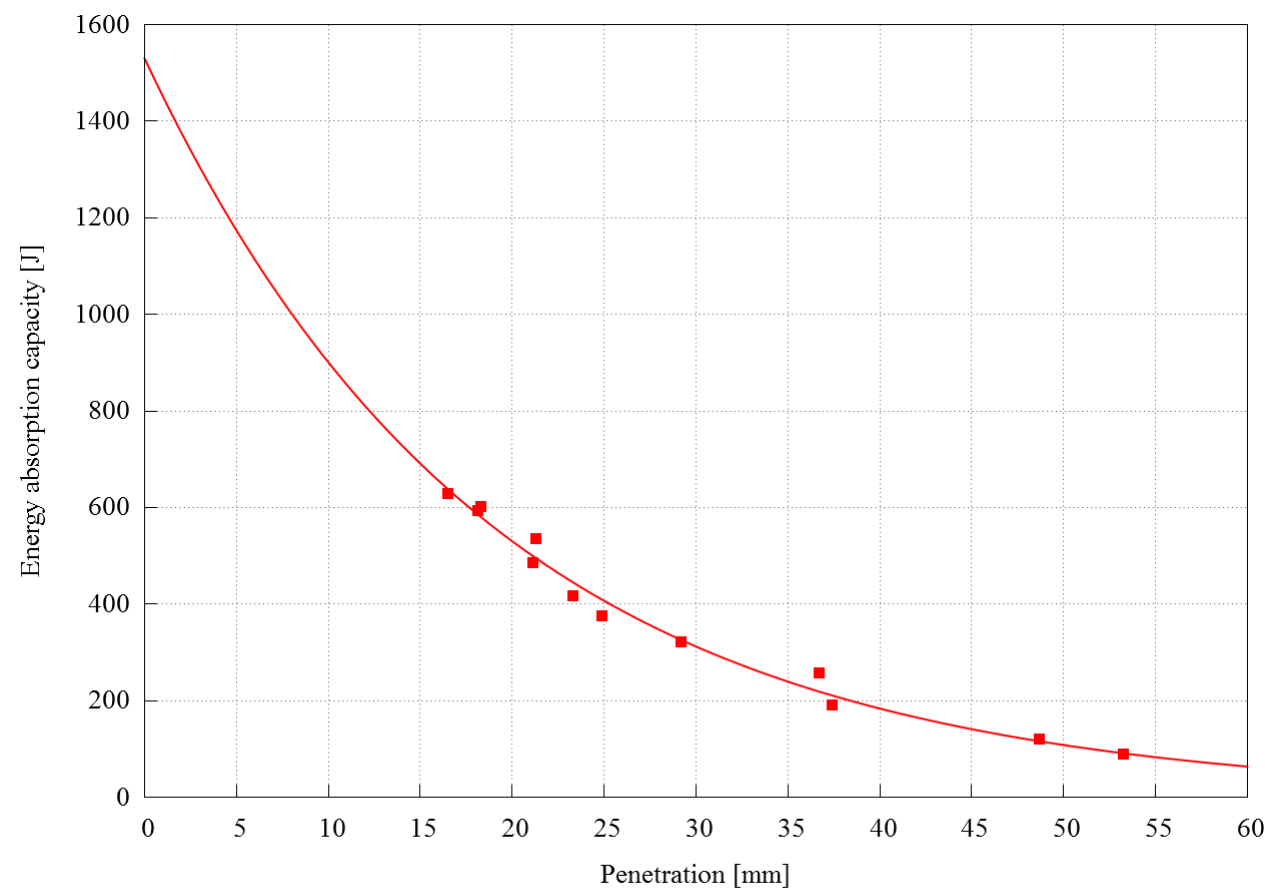

RDP tests series 2

$\mathrm{E}(\mathrm{x})$

Figure 7 Energy absorption capacity as a function of penetration as measured using the stud driving method, after Swedberg (2013). The relation should be used with caution for values of penetration between 0 and $15 \mathrm{~mm}$ since no data points have been obtained in this range 


\subsection{Stud penetration tests on a shotcrete lining}

The stud penetration method was used to determine the early strength of a shotcrete lining in crosscut 407 on the 1,079 $\mathrm{m}$ level in the Kiirunavaara Mine. Eight measurements were performed, between one and $14 \mathrm{~h}$ after spraying. The results are presented in Table 3 . It can be noted that the first three measurements were performed when the concrete was still too fresh, and as a result the stud penetrated its entire length. After the final measurement $14 \mathrm{~h}$ after application, a penetration of $22 \mathrm{~mm}$ was measured. This would be equivalent to about $468 \mathrm{~J}$ of energy absorption capacity in an RDP test, which is about $70 \%$ of the requirement of $650 \mathrm{~J}$ for a 28 day old cast panel.

Table 3 Penetration and calculated energy absorption capacity and UCS for newly sprayed concrete in the Kiirunavaara Mine, after Swedberg (2013)

\begin{tabular}{cccc}
\hline Curing time (h) & Penetration (mm) & $\begin{array}{c}\text { Energy absorption } \\
\text { capacity (J) }\end{array}$ & UCS (MPa) \\
\hline 1.0 & 72 & - & - \\
2.0 & 72 & - & - \\
3.4 & 72 & - & - \\
4.6 & 59.0 & 64 & 3.3 \\
5.9 & 49.8 & 105 & 4.8 \\
7.8 & 33.1 & 258 & 10 \\
12.2 & 24.2 & 416 & 21 \\
14.3 & 22.0 & 468 & $>26$ \\
\hline
\end{tabular}

\section{$4 \quad$ Early strength of rockbolts}

In order to determine the early strength development of cement-grouted rockbolts, a number of pull-out tests have been performed on bolts installed in field conditions. These were divided into two series: one in Kiirunavaara and one in Malmberget. Since the intent was to measure the bond strength development, the tests were performed on bolts with a reduced embedment length.

Pull-out tests were performed on thirteen rockbolts in Kiirunavaara (series 1 ) and 17 rockbolts in Malmberget (series 2). The geology of the test site in Kiirunavaara consisted of syenite porphyry, which is generally hard and competent. In Malmberget, the tests were performed in very weak and altered biotite shale. Since shotcrete was already applied at the test sites, detailed joint mapping could not be performed.

The results are presented in Figure 8 as a value for the shear resistance, in order to be able to compare rockbolts with different embedment length. In both series, the rapid strength development initiates around six hours after grouting, and levels out after around $24 \mathrm{~h}$. However, in series 2 , there is significant variance in the measured shear resistance even after $24 \mathrm{~h}$. One reason for this is likely to be the weak rock in which the second series was performed.

According to Equation (1), a shear resistance of $4 \mathrm{MPa}$ is required in order to be able to mobilise the failure load of the rockbolts. In these tests, $4 \mathrm{MPa}$ is clearly achieved after $19 \mathrm{~h}$ in series 1 . On the other hand, series 2 provides inconclusive data, with some bolts reaching $4 \mathrm{MPa}$ in as little as $15 \mathrm{~h}$ and others were pulled out at very low loads. 


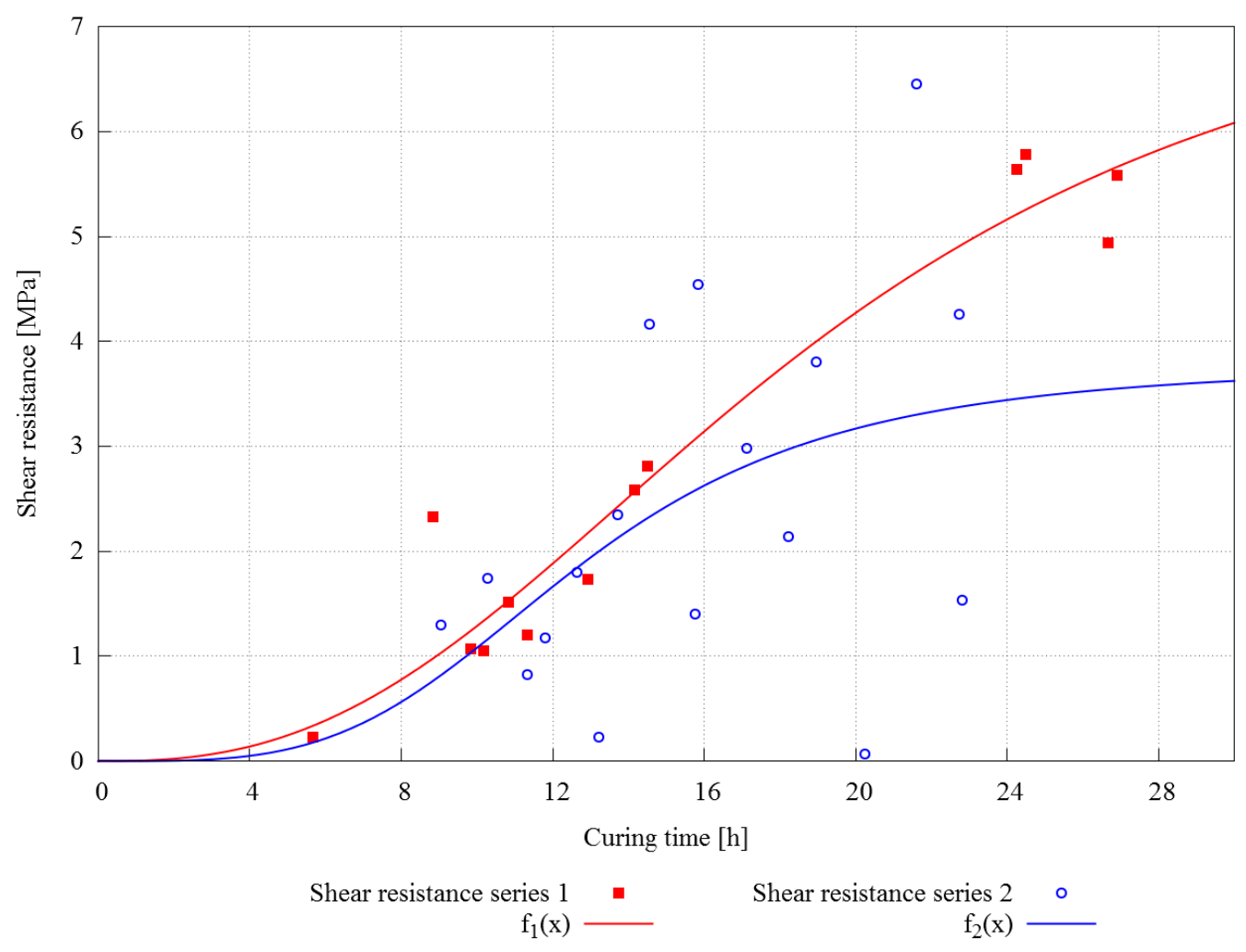

Figure 8 Shear resistance as a function of curing time measured in the two series of pull tests, after Swedberg (2013)

\section{$5 \quad$ Impact of shotcrete thickness for external and embedded steel mesh}

LKAB applies steel fibre reinforced shotcrete to the roof and walls of all newly developed drifts and crosscuts underground. Welded steel mesh is bolted on top of the shotcrete in areas where seismic events or large deformations of the rock mass are expected. In areas that require a strong and stiff rock support, steel mesh is embedded inside the shotcrete. This is done by first installing steel mesh on the rock which is then covered by shotcrete.

\subsection{Panels with/without external and embedded steel mesh}

The performance of shotcrete fitted with external steel mesh and shotcrete reinforced with embedded steel mesh were studied in laboratory tests. The tests used centrally loaded RDPs made of concrete from the same mix as used for shotcrete. To determine the effect that the steel mesh has on the total strength, tests were performed on panels made without, as well as with, mesh reinforcement.

A total of 28 panels of different thicknesses were tested according to the ASTM C1550 standard (ASTM International 2012) as described above. Also, the performance of the RDPs was mainly evaluated from the load carrying capacity instead of energy absorbing capacity. The tests were divided into three parts. The first part consisted of RDPs with fibre reinforced concrete, which were cast in three different thicknesses of 50, 75 and $100 \mathrm{~mm}$, four panels of each. In the second part, an identical set of panels were cast, with the addition of a steel mesh attached under each panel as shown in Figure 9. In the third part, four panels were cast with a thickness of $75 \mathrm{~mm}$ with an embedded steel mesh inside each panel. 


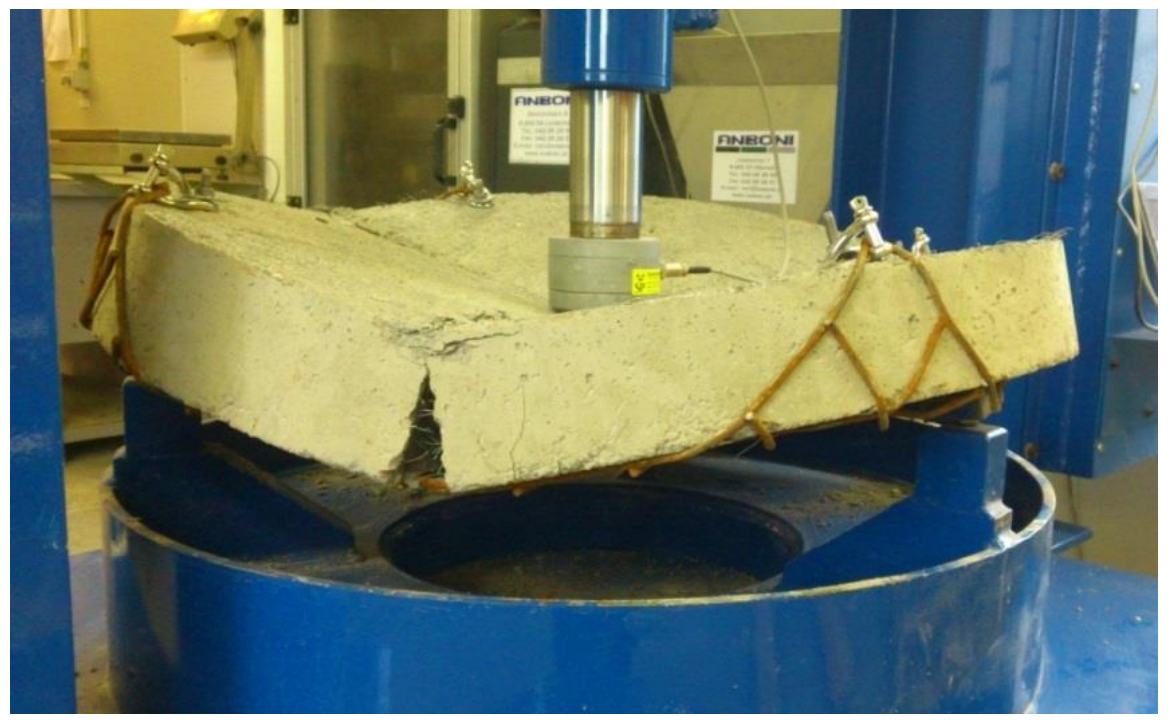

Figure 9 Testing of a $100 \mathrm{~mm}$ thick RDP with external steel mesh

The results from the first part showed that the load carrying capacity of the panels increased with the panel thickness. However, the load carrying capacity approached the same residual value for all panels, regardless of thickness, as the deflection increased. Figure 10 shows the results from the testing of the RDPs casted from fibre reinforced concrete without steel mesh.

The panels in the second part showed an improved residual load carrying capacity due to the external steel mesh attached to the panels. Unlike the results from the first part, the residual load for each panel thickness reached different values at large deflections. The 75 and $100 \mathrm{~mm}$ thick panels did even show an increase of load carrying capacity after a deflection of 50-60 $\mathrm{mm}$.

Part three only consisted of $75 \mathrm{~mm}$ thick RDPs with steel mesh embedded in the panels at casting. These panels had the highest residual load carrying capacity, and initially showed a nearly perfectly plastic deformation. The entire steel mesh was not able to yield since the mesh was embedded in the concrete. The effect of this was shown during the tests when strands in the steel mesh began to fail after a panel deflection of around 50-70 $\mathrm{mm}$. As more strands failed the load carrying capacity of the panels decreased significantly. The results from the testing of the RDPs with external steel mesh and the RDPs with embedded steel mesh are shown in Figures 11 and 12, respectively.

The energy absorbing capacity for all $75 \mathrm{~mm}$ thick panels of the three panel types were compared at $80 \mathrm{~mm}$ deflection. The comparison showed that the panels with embedded and external steel mesh had a higher mean value for absorbed energy with a factor of 1.7 and 2.4 respectively, compared to the panels without steel mesh. The mean values of absorbed energy at $80 \mathrm{~mm}$ deflection for the $75 \mathrm{~mm}$ thick panels in the three parts are shown in Table 4.

Table 4 Mean values of absorbed energy at $80 \mathrm{~mm}$ deflection for the $75 \mathrm{~mm}$ thick RDPs of the different types, after Thyni (2014)

\begin{tabular}{cccc}
\hline & Fibre reinforced concrete & External steel mesh & Embedded steel mesh \\
\hline Absorbed energy $(J)$ & 1,036 & 1,808 & 2,505 \\
\hline
\end{tabular}




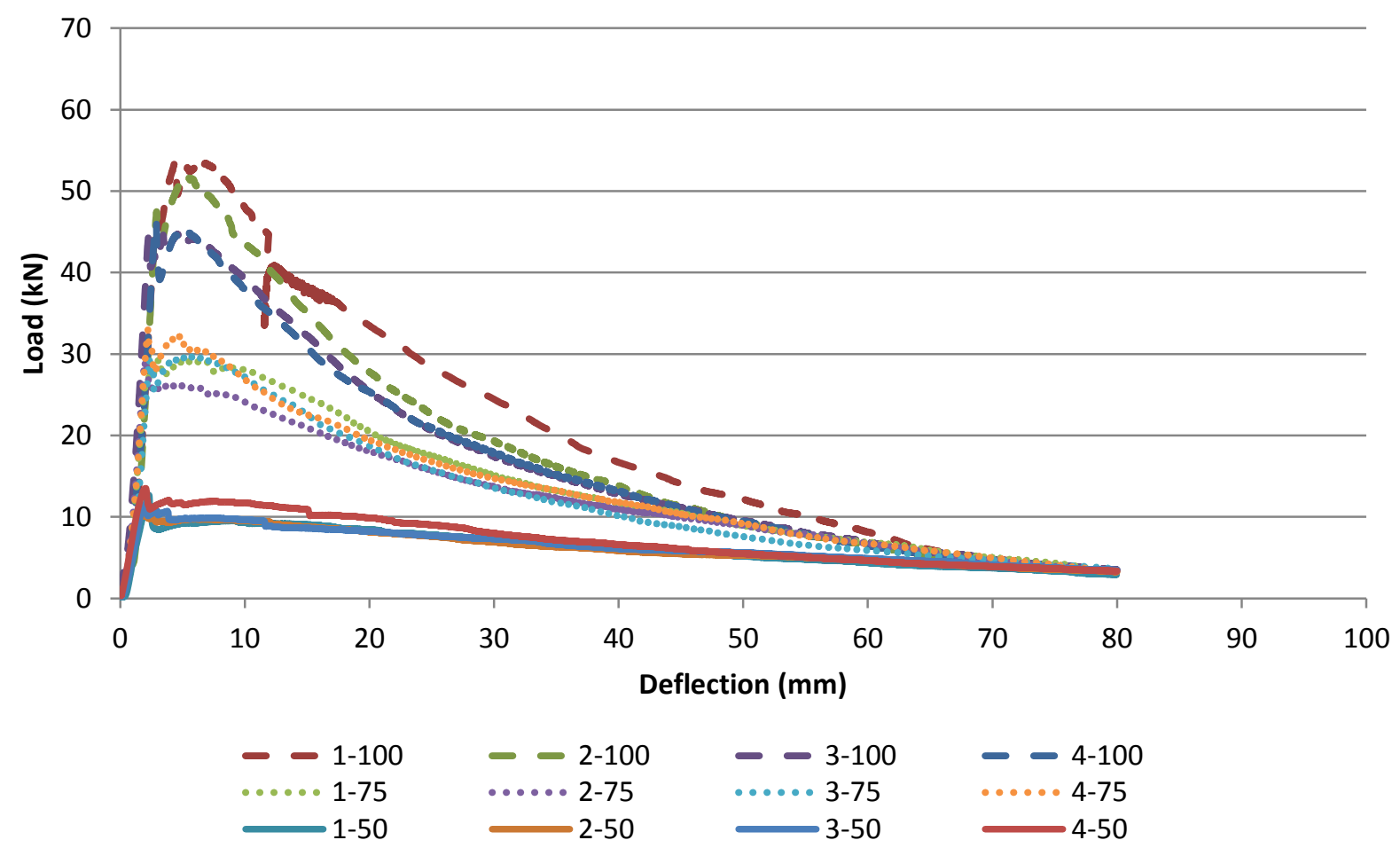

Figure 10 Results from the testing of the RDPs without steel mesh, after Thyni (2014)

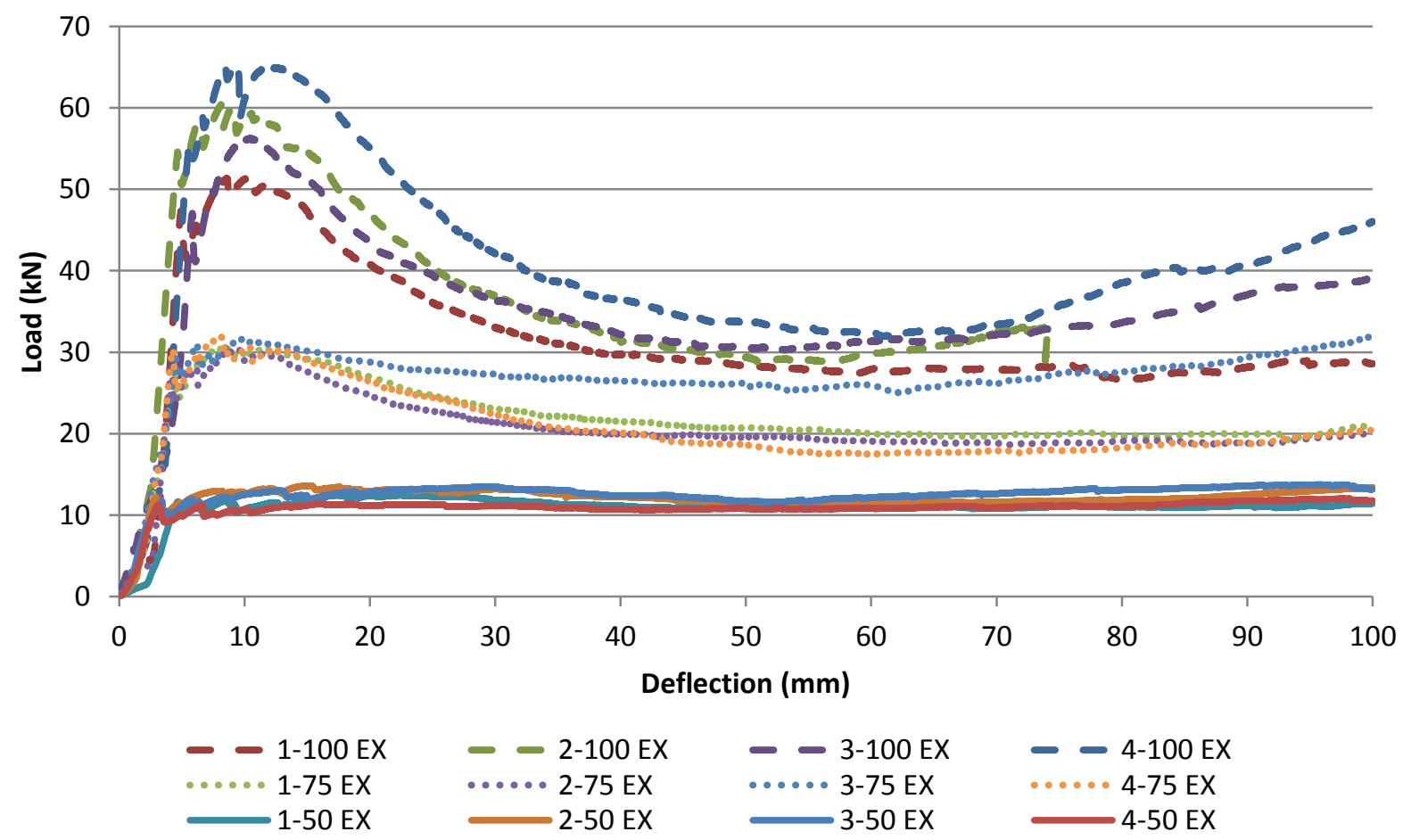

Figure 11 Results from the testing of the RDPs with external steel mesh, after Thyni (2014) 


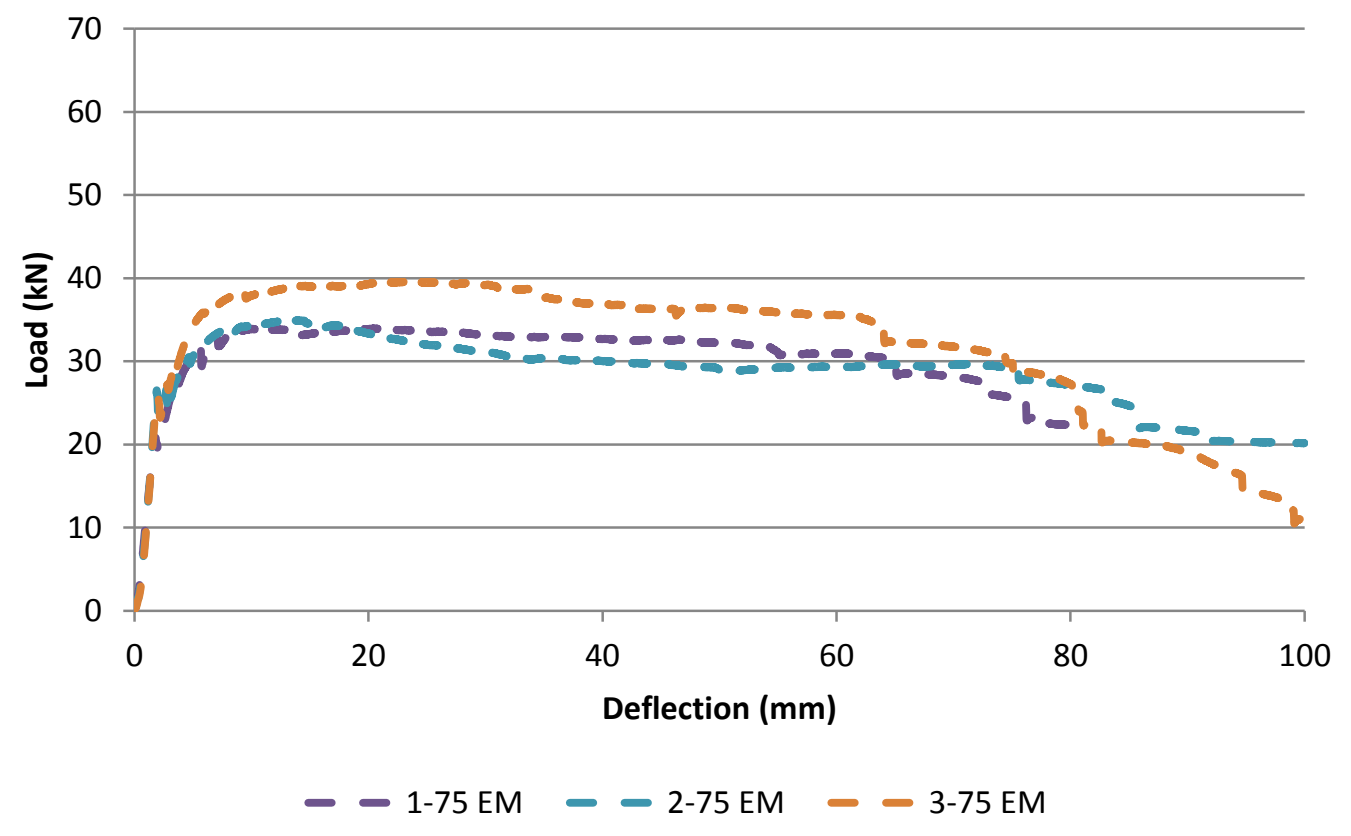

Figure 12 Results from the testing of the RDPs with embedded steel mesh, after Thyni (2014)

\subsection{Comparison of panels with/without external and embedded steel mesh}

Comparing the mean values of absorbed energy between the panels reinforced with only steel fibres and the panels with external mesh, it its clearly shown that the external steel mesh gives significantly higher residual strength to the panels.

Since the panels reinforced with only steel fibres were tested to a deflection of only $80 \mathrm{~mm}$, a direct comparison cannot be made with the corresponding steel mesh equipped panels at deflections exceeding $80 \mathrm{~mm}$. By studying the trends of the load deflection curves for the two panel types, it is likely that the differences in load bearing capacity will increase at larger deflections.

From the three different panel types it can be concluded that in the residual state, the panels with embedded steel mesh showed a significantly higher strength than the other panels. However, the mesh strands in the embedded mesh began to fail at deflections of around $50-70 \mathrm{~mm}$, causing a substantial loss of load carrying capacity. The same deflections of the panels with external steel mesh did not show any damage to the steel mesh. Instead, a slight increase of load carrying capacity was observed for the $75 \mathrm{~mm}$ thick panels with external mesh. This increase was even larger for the $100 \mathrm{~mm}$ thick panels with external mesh, which suggests that external mesh is more favourable for rock support subjected to large deformations.

\section{Conclusions}

Three aspects of the design and testing of rock support were examined by different tests, focussing on:

1. The early strength development for grouted rockbolts and shotcrete.

2. The impact of shotcrete thickness.

3. The placement of the steel mesh, i.e. embedded or external, on the load bearing capacity of a rock support system.

Pull-out tests on rockbolts and stud penetration tests in a shotcrete liner were conducted in the field, while RDP tests were performed in a laboratory environment. RDP tests were performed on fibre reinforced shotcrete panels with and without external steel mesh, as well as shotcrete panels with and without steel fibres reinforced with embedded steel mesh. 
The following conclusions can be drawn from the performed tests.

- Cast RDPs achieve an energy absorption capacity of $630 \mathrm{~J}$ (as measured according to ASTM C1550 (ASTM International 2012)) after $36 \mathrm{~h}$ of curing. This is close to LKAB's requirement of $650 \mathrm{~J}$ after 28 days.

- For sprayed concrete under field conditions, an energy absorption capacity of $468 \mathrm{~J}$ is achieved after $15 \mathrm{~h}$. However, since only one field test was performed, more tests are needed in order to confirm this conclusion.

- A cement-grouted modified Kiruna rebar bolt achieves its failure load when the grout has cured for approximately $19 \mathrm{~h}$.

- Geology has a big influence on the early strength development of cement-grouted rockbolts. In particular, the distribution between high and low pull-out resistances after a specific curing time can be much larger in weak rock.

The tests focusing on the effects of shotcrete thickness when external or embedded mesh is used gave the following conclusions.

- External or embedded steel mesh enhances the energy absorption capacity for rock support with fibre reinforced shotcrete.

- Embedded steel mesh initially improves the residual strength of the shotcrete support more than external steel mesh. However, embedded steel mesh has a limited capacity to yield and thus cannot accommodate very large deformations.

- The shotcrete thickness seems to have a large influence on the strength of a rock support system even if external steel mesh is installed.

- The relative increase of load bearing capacity contributed by the external steel mesh is larger for thicker panels. This indicates that there is interaction between the steel mesh and the shotcrete.

All the above conclusions are based on static testing of rock support elements. In order to obtain definitive conclusions with regard to the dynamic load capacities of the tested elements, dynamic testing is required. However, the presented results are still deemed sufficient for an initial relative comparison between different support elements or configurations.

\section{Acknowledgement}

The authors give a special thanks to the personnel at LKAB who helped prepare, execute and evaluate the tests.

\section{References}

ASTM International 2012, ASTM C1550: Standard Test Method for Flexural Toughness of Fiber Reinforced Concrete (Using Centrally Loaded Round Panel), ASTM International, West Conshohocken, viewed 14 June 2014, http://enterprise.astm.org /filtrexx40.cgi?+REDLINE_PAGES/C1550.htm

Jacobsson, L, Töyrä, J, Woldemedhin, B \& Krekula, H 2013, 'Rock Support in the Kiirunavaara Mine', in Y Potvin \& B Brady (eds), Proceedings of the Seventh International Symposium on Ground Support in Mining and Underground Construction, Australian Centre for Geomechanics, Perth, pp. 401-410.

Sjöberg, J, Lundman, P, Nordlund, E \& Quinteiro, C 2003, 'Stability analysis of ore passes in the Kiirunavaara mine', Proceedings of the 10th Congress of the ISRM - Technology Roadmap for Rock Mechanics, vol. 2, South African Institute of Mining and Metallurgy, pp. 1093-1098.

Swedberg, E 2013, 'Early Strength of Shotcrete and Fully Grouted Rockbolts', in Swedish, Masters thesis, Luleå University of Technology, Luleå.

Swedish Standards Institute 2006, SS-EN 14488-2: Testing sprayed concrete - Part 2: Compressive strength of young sprayed concrete, Swedish Standards Institute, Stockholm, viewed 14 June 2014, http://www.sis.se/en/construction-materials-andbuilding/construction-materials/concrete-and-concrete-products/ss-en-14488-22006

Thyni, F 2014, 'Design of Shotcrete for Dynamic Rock Support by Static Testing', Masters thesis, Luleå University of Technology, Luleå. 